Methods: Data from 2,846 unselected patients of the European Map of Axial Spondyloarthritis (EMAS) through an online survey (2017-2018) across 13 countries were analysed. The impact of axSpA on patients' sexual life was evaluated by a question assessing changes in the frequency of intimate relations since the onset of axSpA on a 5 point Likert scale. Impact of axSpA on the spousal relationship since disease onset was also assessed using 5 point Likert scale. Other lifestyle variables included smoking and physical activity and burden of disease [BASDAI (0-10), spinal stiffness (3-12), functional limitation in intimate relations (0-2), and psychological distress (GHQ-12)]. Regression analysis were carried out to determine the relative weight of the assessed variables.

Results: EMAS total sample mean age was 43.9 years, $61.3 \%$ were female, $48.1 \%$ had a university degree, and $67.9 \%$ were married. Out of the 2,515 participants that reported on the frequency of intimate relations since disease onset, $56.4 \%$ declared that it was less or much less than before; $74.1 \%$ declared high or medium limitation in intimate relations; and $30.4 \%$ reported worsening relations with their spouse. A lower frequency of intimate relations was related to: older age, female gender, higher BASDAI, spinal stiffness, higher functional limitation in intimate relations, higher psychological distress, self-reported diagnosis of depression, worsening relationship with spouse since disease onset, higher BMI, smoking, lack of physical activity, and lack of biologics use. In the multivariate regression analysis, the most strongly associated variables with lower frequency of intimate relations were: functional limitation in intimate relations $(\beta=0.218 ; 95 \% \mathrm{Cl} 0.185-0.251)$, worse relationship with spouse $(\beta=0.207 ; 95 \% \mathrm{Cl}=0.165-0.250)$, female gender $(\beta=0.150$; $95 \% \mathrm{Cl} 0.071-0.229)$, and no engaging in physical activity $(\beta=-0.135 ; 95 \%$ Cl $-0.234--0.036$ ) (Table 2).

Conclusion: EMAS results reveal a great impact of axSpA on patients' sexual life, with multiple sociodemographic, lifestyle and PROs being associated with a lower frequency of intimate relations.

Table 1. Regression analysis to predict frequency of intimate relations

\begin{tabular}{|c|c|c|c|c|c|c|}
\hline & \multicolumn{3}{|c|}{ Simple linear regression } & \multicolumn{3}{|c|}{ Multivariable stepwise linear regression } \\
\hline & B & $95 \% \mathrm{Cl}$ & $\mathrm{p}$ & $\mathrm{B}$ & $95 \% \mathrm{Cl}$ & $\mathrm{p}$ \\
\hline Age (Years) & 0.007 & $0.004,0.010$ & $<0.001$ & 0.010 & $0.007,0.013$ & $<0.001$ \\
\hline Gender (Female) & 0.215 & $0.146,0.284$ & $<0.001$ & 0.150 & $0.071,0.229$ & $<0.001$ \\
\hline BASDAI & 0.124 & $0.107,0.141$ & $<0.001$ & 0.029 & $0.007,0.050$ & 0.010 \\
\hline Spinal Stiffness & 0.089 & $0.075,0.102$ & $<0.001$ & NA & NA & 0.214 \\
\hline $\begin{array}{l}\text { Functional Limitation } \\
\text { - Intimate } \\
\text { relations }\end{array}$ & 0.297 & $0.271,0.323$ & $<0.001$ & 0.218 & $0.185,0.251$ & $<0.001$ \\
\hline GHQ-12 & 0.067 & $0.059,0.075$ & $<0.001$ & 0.035 & $0.024,0.045$ & $<0.001$ \\
\hline Depression (Yes) & 0.375 & $0.298,0.452$ & $<0.001$ & NA & NA & 0.064 \\
\hline $\begin{array}{l}\text { Relationship with } \\
\text { spouse }\end{array}$ & 0.343 & $0.306,0.380$ & $<0.001$ & 0.207 & $0.165,0.250$ & $<0.001$ \\
\hline BMI & 0.017 & $0.011,0.024$ & $<0.001$ & 0.008 & $0.001,0.015$ & 0.031 \\
\hline Smoking (Yes) & 0.075 & $0.002,0.148$ & 0.044 & NA & NA & 0.907 \\
\hline $\begin{array}{l}\text { Physical activity } \\
\text { (Yes) }\end{array}$ & -0.212 & $-0.306,-0.119$ & $<0.001$ & -0.135 & $-0.234,-0.036$ & 0.007 \\
\hline Biologics (Yes) & 0.188 & $0.110,0.267$ & $<0.001$ & NA & NA & 0.185 \\
\hline
\end{tabular}

Acknowledgments: Funded by Novartis Pharma AG

Disclosure of Interests: Marco Garrido-Cumbrera: None declared, Christine Bundy Grant/research support from: Has received unrelated honoraria from Abbvie, Celgene, Janssen, Lilly, Novartis, and Pfizer., Denis Poddubnyy Grant/research support from: AbbVie, MSD, Novartis, and Pfizer, Consultant of: AbbVie, Bristol-Myers Squibb, Eli Lilly, MSD, Novartis, Pfizer, Roche, UCB, Speakers bureau: AbbVie, Bristol-Myers Squibb, Eli Lilly, MSD, Novartis, Pfizer, Roche, UCB, Souzi Makri: None declared, Raj Mahapatra: None declared, Sergio Sanz-Gómez: None declared, Laura Christen: None declared, Carlos Jesús Delgado-Domínguez: None declared, Victoria Navarro-Compán Consultant of: Abbvie, Lilly, Novartis, Pfizer, UCB, Speakers bureau: AbbVie, MSD, Lilly, Novartis, Pfizer, UCB DOI: 10.1136/annrheumdis-2020-eular.4277

\section{GROWTH AND DEVELOPMENT OF CHILDREN FROM} MOTHERS WITH ANKYLOSING SPONDYLITIS

S. H. Chang ${ }^{1}$, I. A. Choi ${ }^{2}$, J. Kim², S. W. Lee ${ }^{1}$, H. J. Kim ${ }^{3}$, H. S. Ahn ${ }^{3}$. ${ }^{1}$ Soonchunhyang University College of Medicine Cheonan Hospital, Internal Medicine, Rheumatology, Cheonan, Korea, Rep. of (South Korea); ${ }^{2}$ Chungbuk National University Hospital, Internal Medicine, Rheumatology, Chungju, Korea, Rep. of (South Korea); ${ }^{3}$ Korea University College of Medicine, Preventive Medicine, Seoul, Korea, Rep. of (South Korea)

Background: Ankylosing spondylitis (AS) is a chronic inflammatory disease featured with involvement of sacroiliac joint and starts in the second or third decade of life. Female patients with AS are mostly in childbearing ages. There are several studies of pregnancy outcomes but no studies about their offsprings.

Objectives: The objective of our study was to invetigate the growth and developement of offsprings from AS mothers.

Methods: This is a nationwide population-based case-control study using two South Korean databases that are managed by the National Health Insurance Service (NHIS): (1) the National Health Screening Program for Infants and Children (NHSIC) database, which records screening data of the growth and development of all children; (2) the NHIS database, which covers the entire population and includes comprehensive health claims data. In Korea, the NIH supports patients with 133 rare severe, intractable diseases including AS via a registration system of rare intractable disease (RID). We enrolled subjects born from 2008-2013 who had participated in the NHSIC program at three consecutive times; during 4-6 months (1st), 9-12 months (2nd), either 54-65months or 66-71 months (6th, 7th). The Korean Developmental screening test (K-DST) was used to assess development. By linking maternal and offspring healthcare data through their unique personal identification numbers, we constructed a mother-child database to track the growth of the child. We classified childrens from AS mothers using RID sys tem (ICD code M45.X) and those from non-AS mothers. The primary outcome was to compare the growth and developement of offsprings from AS mothers and those from general popuulation. The secondary outcome was to copare the growth and developement of offsprings from mothers who diagnosed AS before delivery (ante-partum, AS-AP) and those from mothers who diagnosed AS after delivery (postpartum, AS-PP). Low birth weight (LBW) was defined as a birth weight below $2500 \mathrm{~g}$. Growth retardation (GR) was defined as a body wight below 10th percentile according to birth weight reference curves for the south Korean population.

Results: A total of 794,544 subjects were identified. Among those cohort subject, there were 369 subjects with AS mother (124 subjects from AS-AP, 245 subjects from AS-PP) while 794,175 subjects with non-AS mother. Offsprings with LBW were comparable between those from AS mother and non-AS mother (OR 1.3, $95 \% \mathrm{Cl}$ 0.74-2.02). At 4-6 months, an OR of GR was comparable between two groups (OR 1.18, 95\% Cl 0.72-1.92) but increased at 9-12 months (OR 1.62, $95 \% \mathrm{Cl} 1.14-2.31)$ in infants from AS mothers. This difference disappered at $54-71$ months (OR $0.24,95 \% \mathrm{Cl} 0.87-1.74$ ). An OR of development abnormality (i.e. children needed the further evaluation or the follow-up test by K-DST) was also comparable between two groups (OR 0.94, 95\% Cl 0.71-1.25). Mothers with AS-AP had as about three times as a higher OR for having babies with LBW than mothers with AS-PP (OR 2.8, 95\% Cl 1.15-6.86). At 4-6 months, an OR of GR was comparable between two groups (OR $0.59,95 \% \mathrm{Cl} 0.19-1.86$ ) but decreased at 9-12 months (OR $0.39,95 \% \mathrm{Cl} 0.16-0.98$ ) in infants from AS-PP. This difference disappered at 54-71months (OR 0.63,95\% Cl 0.29-1.39). An OR of development abnormality (i.e. children needed the further evaluation or the follow-up test by K-DST) was also comparable between two groups (OR 1.37, 95\% Cl 0.77-2.43).

Conclusion: Growth and development of children from AS mothers were comparable with those from non-AS mothers. Although mothers with AS-AP had significantly higher ORs for having LBW babies than those with AS-PP, their growth and development were comparable between two groups in young childhood.

Disclosure of Interests: None declared

DOI: 10.1136/annrheumdis-2020-eular.3682

\section{Pain pathology, progression and pharmacotherapy_}

OP0083
MORSAL ROOT GANGLIA INFILTRATING
MACROPHAGES MAINTAIN OSTEOARTHRITIS PAIN

R. Raoof ${ }^{1}$, C. Martin ${ }^{1}$, H. De Visser ${ }^{1}$, J. Prado ${ }^{1}$, S. Versteeg ${ }^{1}$, A. Heinemans ${ }^{1}$, S. Mastbergen ${ }^{1}$, F. Lafeber ${ }^{1}$, N. Eijkelkamp ${ }^{1} .{ }^{1}$ UMC Utrecht, Utrecht, Netherlands

Background: Pain is a major debilitating symptom of knee osteoarthritis $(\mathrm{OA})$. However, the extent of joint damage in OA does not correlate well with the severity of pain. The mechanisms that govern OA pain are poorly understood. Immune cells infiltrating nervous tissue may contribute to pain maintenance.

Objectives: Here we investigated the role of macrophages in the initiation and maintenance of OA pain.

Methods: Knee joint damage was induced by an unilateral injection of mono-iodoacetate (MIA) or after application of a groove at the femoral condyles of rats fed on high fat diet. Pain-like behaviors were followed over time using von Frey test and dynamic weight bearing. Joint damage was assessed by histology. Dorsal root ganglia (DRG) infiltrating immune cells were assessed over time using flow cytometry. To deplete monocytes and 
macrophages, Lysm ${ }^{\text {cre }} \times$ Csfr1-Stop-DTR were injected intrathecal or systemically with diptheria toxin (DT).

Results: Intraarticular monoiodoacetate injection induced OA and signs of persistent pain, such as mechanical hyperalgesia and deficits in weight bearing The persisting pain-like behaviors were associated with accumulation of $\mathrm{F} 4 / 80^{+}$ macrophages with an M1-like phenotype in the lumbar DRG appearing from 1 week after MIA injection, and that persisted till at least 4 weeks after MIA injection. Macrophages infiltrated DRG were also observed in the rat groove model of OA, 12 weeks after application of a groove at the femoral condyles. Systemic or local depletion of DRG macrophages during established MIA-induced OA completely ablated signs of pain, without affecting MIA-induced knee pathology. Intriguingly when monocytes/macrophages were depleted prior to induction of osteoarthritis, pain-like behaviors still developed, however these pain-like behaviors did not persist over time. In vitro, sensory neurons innervating the affected $\mathrm{OA}$ joint programmed macrophages into a M1 phenotype. Local repolarization of M1-like DRG macrophages towards M2 by intrathecal injection of M2 macrophages or anti-inflammatory cytokines resolved persistent OA-induced pain.

Conclusion: Overall we show that macrophages infiltrate the DRG after knee damage and acquire a M1-like phenotype and maintain pain independent of the lesions in the knee joint. DRG-infiltrating macrophages are not required for induction of OA pain. Reprogramming M1-like DRG-infiltrating macrophages may represent a potential strategy to treat $O A$ pain.

Acknowledgments: This project has received funding from the European Union's Horizon 2020 research and innovation programme under the Marie Sklodowska-Curie grant agreements No 814244 and No 642720. Dutch Arthritis Society

Disclosure of Interests: Ramin Raoof: None declared, Christian Martin: None declared, Huub de Visser: None declared, Judith Prado: None declared, Sabine Versteeg: None declared, Anne Heinemans: None declared, Simon Mastbergen: None declared, Floris Lafeber Shareholder of: Co-founder and shareholder of ArthroSave BV, Niels Eijkelkamp: None declared

DOI: 10.1136/annrheumdis-2020-eular.4354

\section{\begin{tabular}{|l|l}
\hline OP0084 PRESSURE PAIN THRESHOLDS AND THE \\
\hline
\end{tabular} ASSOCIATIONS WITH CHRONIC WIDESPREAD PAIN, KNEE OSTEOARTHRITIS AND OBESITY IN INDIVIDUALS WITH KNEE PAIN}

C. Sylwander $^{1,2}$, E. Haglund ${ }^{1,3,4}$, I. Larsson ${ }^{1,2,4}$, S. Bergman ${ }^{1,4,5}$, M. Andersson ${ }^{1,4}$. ${ }^{1}$ Spenshult Research and Development Centre, Halmstad, Sweden; ${ }^{2} \mathrm{Halmstad}$ University, School of Health and Welfare, Halmstad, Sweden; ${ }^{3} \mathrm{Halmstad}$ University, School of Business, Engineering and Science, Halmstad, Sweden; ${ }^{4}$ Lund University, Department of Clinical Sciences, Section of Rheumatology, Lund, Sweden; ${ }^{5}$ The Sahlgrenska Academy, University of Gothenburg, Primary Health Care Unit, Department of Public Health and Community Medicine, Institute of Medicine, Gothenburg, Sweden

Background: Approximate $30 \%$ of individuals with symptomatic knee osteoarthritis (OA) had developed chronic widespread pain (CWP) over a period of 20 years [1]. In order to prevent CWP in those with knee pain, it is important to study associated factors.

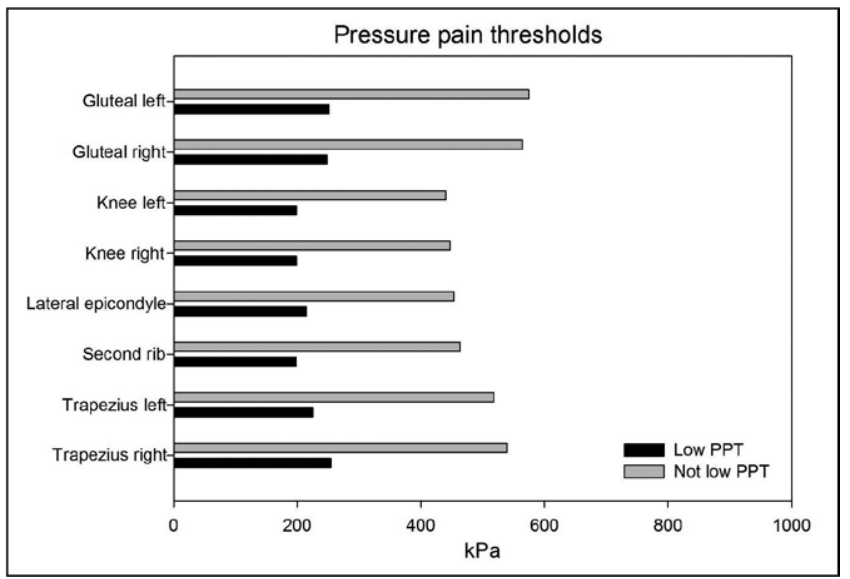

Figure 1 Differences in mean PPT in the eight tender points
Objectives: The aim was to study pressure pain thresholds among individuals with knee pain with or without radiographic changes, and associations with CWP radiographic knee $O A$, and obesity.

Methods: Out of 300 individuals with knee pain (with or without radiographic changes) from an ongoing longitudinal study, 279 conducted pressure pain thresholds (PPT) measurement at baseline in this cross-sectional study $(71 \%$ women; mean age 51 years). The PPT were measured using a computerized pressure algometry on eight predefined tender points (Figure 1) out of the 18 points as part of the definition of fibromyalgia [2]. PPTs were dichotomised based on the lowest tertial vs the two higher tertials for each of the eight points. A group that had $\geq 4$ points with low PPT (low PPT group) was compared to a group that had $<4$ low PPT (not low PPT group). A pain mannequin categorised the participants in three different pain groups: CWP, chronic regional pain (CRP), and no chronic pain (NCP) according to the definition of the ACR [2] Radiographic knee OA was defined according to the Ahlbäck five grading scale as having score $\geq 1$ vs score 0 [3]. Obesity was measured by bioimpedance measuring $\mathrm{BMI}$ and visceral fat area (VFA, $\mathrm{cm}^{2}$ ). To study associations, a crude logistic regression model controlled for age and sex was used including main and significant variables

Results: The prevalence of CWP was 37\% and higher in the low PPT group compared to those in the not low PPT group (Table 1). No differences were found between the groups in BMI, VFA or radiographic knee OA (Table 1). The low PPT group had significantly lower mean PPT on all eight tender points, was younger, had more pain sites, and more cases of fibromyalgia compared to the group with not low PPT (Table 1, Figure 1). Age (OR 0.95; 95\% Cl 0.92-0.97), having CWP (OR 3.00; Cl 1.66-5.06), fibromyalgia (OR 21.91; Cl 2.45-194.69) and increased number of pain sites (OR 1.13; $\mathrm{Cl} 1.05-1.22)$ were associated with low PPT.

Table 1. Descriptive statistics for the whole sample and for the groups: low PPT and not low PPT

\begin{tabular}{lcccc}
\hline & $\begin{array}{c}\text { All } \\
\mathrm{n}=279\end{array}$ & $\begin{array}{c}\text { Low PPT } \\
\mathrm{n}=99\end{array}$ & $\begin{array}{c}\text { Not low PPT } \\
\mathrm{n}=180\end{array}$ & p-value \\
\hline Age, mean years (sd) & $51(9)$ & $49(9)$ & $53(8)$ & $<0.001$ \\
Women, $\mathrm{n}(\%)$ & $197(71 \%)$ & $69(70 \%)$ & $128(71 \%)$ & 0.804 \\
Pain group, $\mathrm{n}(\%)$ & & & & $<0.001$ \\
$\quad$ NCP/CRP & $160(63 \%)$ & $41(47 \%)$ & $119(71 \%)$ & \\
$\quad$ CWP & $95(37 \%)$ & $46(53 \%)$ & $49(29 \%)$ & \\
Numbers of pain sites, mean (sd) & $5(4)$ & $6(5)$ & $4(3)$ & 0.003 \\
Fibromyalgia, $\mathrm{n}(\%)$ & $8(3 \%)$ & $7(9 \%)$ & $1(1 \%)$ & 0.001 \\
Knee OA Ahlbäck, n (\%) & $59(23 \%)$ & $16(18 \%)$ & $43(26 \%)$ & 0.132 \\
BMI, n (\%) & $127(48 \%)$ & $42(47 \%)$ & $85(48 \%)$ & 0.801 \\
$\quad$ Normal Overweight/Obese & $139(52 \%)$ & $48(53 \%)$ & $91(52 \%)$ & \\
VFA, mean cm ${ }^{2}$ (sd) & $114(54)$ & $115(51)$ & $113(55)$ & 0.788 \\
\hline
\end{tabular}

Conclusion: Baseline characteristics of individuals with knee pain showed a higher prevalence of CWP than in the general population [4]. In the group with low PPT, the prevalence was even higher. The study found associations between CWP and low PPT, however, almost half of the individuals with low PPT reported NCP/CRP. Moreover, a third in the group that not had low PPT reported CWP. The development of widespread pain in individuals with knee pain needs to be further studied over time to increase the knowledge of CWP's origin in order to prevent the condition.

References:

[1] Bergman et al. BMC Musculoskelet Disord. 2019;20:592

[2] Wolfe et al. Arthritis Rheum. 1990;33:160-72

[3] Ahlbäck. Acta Radiol Diagn (Stockh). 1968:7-72

[4] Andrews et al. Eur J Pain. 2018;22:5-18

Disclosure of Interests: None declared

DOI: 10.1136/annrheumdis-2020-eular.2289

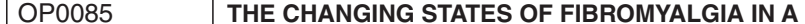 LONGITUDINAL COHORT OF PATIENTS WITH AXIAL SPONDYLOARTHRITIS}

S. Aarrestad Provan ${ }^{1,2}$, L. Dean ${ }^{1}$, G. T. Jones ${ }^{1}$, G. Macfarlane ${ }^{1} .{ }^{1}$ University of Aberdeen School of Medicine, Medical Sciences and Nutrition, Epidemiology Group, Aberdeen, United Kingdom; ${ }^{2}$ University of Aberdeen School of Medicine, Medical Sciences and Nutrition, Aberdeen, United Kingdom

Background: The identification of predictors for longitudinal fibromyalgia (FM) development has been identified as a research priority in a recent systematic review and meta-analyses (1). This paper examines the 